\title{
pH-Induced Coacervation in Complexes of Bovine Serum Albumin and Cationic Polyelectrolytes
}

\author{
K. Kaibara ${ }^{\dagger}$ T. Okazaki, ${ }^{\dagger}$ H. B. Bohidar, ${ }^{\ddagger}$ and P. L. Dubin ${ }^{\star} \ddagger$ \\ Department of Chemistry, Faculty of Sciences, Kyushu University, Higashi-ku, Fukuoka 812, Japan, and \\ Department of Chemistry, Indiana-Purdue University, Indianapolis, Indiana 46202
}

Turbidity and light scattering measurements, along with phase contrast microscopy, were used to follow the processes leading to coacervation when aqueous solutions of bovine serum albumin (BSA) and poly(dimethyldiallylammonium chloride) (PDADMAC) were brought from $\mathrm{pH}=4$ to 10 . The state of macromolecular assembly of complexes formed between BSA and PDADMAC prior to and during the $\mathrm{pH}$-induced coacervation could be characterized by specific $\mathrm{pH}$ values at which recognizable transitions took place. In addition to the two characteristic $\mathrm{pH}$ values $\left(\mathrm{pH}_{\text {crit }}\right.$ and $\left.\mathrm{pH}_{\phi}\right)$ previously identified through turbidimetry, other transitions were explicitly established. On the basis of the $\mathrm{pH}$-induced evolution of scattering intensity measurements, we concluded that the formation of soluble primary protein-polymer complexes is initiated at $\mathrm{pH}_{\text {crit }}$ and proceeds until " $\mathrm{pH}_{\text {crit }}^{\prime}$ ". A subsequent increase in scattering intensity at " $\mathrm{pH}_{\mathrm{pre}}$ " may arise from the assembly of quasi-neutralized primary complexes as their net positive charge decreases with increase in $\mathrm{pH}$. Subsequently, a maximum in scattering intensity at $\mathrm{pH}_{\phi}$ is observed coincident with the appearance of turbidity and also corresponding to the first microscopic observation of coacervate droplets. The temperature independence of $\mathrm{pH}_{\text {crit }}$ and $\mathrm{pH}_{\phi}$ suggests that hydrophobic contributions are negligible for the initial BSA-PDADMAC interactions and the subsequent coacervation process. The $\mathrm{pH}$ dependence of scattering intensity profiles allowed the identification of two other transitions beyond $\mathrm{pH}_{\phi}$. Spherical microcoacervate droplets first observed around $\mathrm{pH}_{\phi}$ subsequently displayed morphological changes at " $\mathrm{pH}_{\text {morph" }}$ ", followed by the transformation to solid or flocculant substances at $\mathrm{pH}_{\text {precip. }}$

\section{Introduction}

Protein-polyelectrolyte interactions, primarily arising from electrostatic forces, often lead to coacervation as described in the pioneering work of Bungenberg de Jong. ${ }^{1}$ During this process, a homogeneous aqueous solution undergoes liquidliquid-phase separation giving rise to a dense protein-rich phase. This phenomenon has been of interest from a basic physicochemical point of view, as well as from the perspective of the development of a large variety of possible applications. The unique characteristics of the coacervate phase suggest it as a model for proteins in cytoplasm-like environments. The properties of biological macromolecules in self-organized systems can be examined by studies of the coacervate state. Investigation of protein-polyelectrolyte complexes can prove useful in development of medical devices and artificial organs including cell attachment and scaffolding in biological tissues. Protein-polyelectrolyte coacervation may be applied to a protein separation process, ${ }^{2,3}$ in which purification and recovery of a target protein depend on control of coacervation via $\mathrm{pH}$ or ionic strength. ${ }^{4-6}$ Protein-polyelectrolyte coacervation may be used to immobilize enzymes, an attractive alternative to microcapsulation, if these enzymes can be more active, selective, or

\footnotetext{
* Corresponding author: dubin@ chem.iupui.edu

†yushu University.

$\doteqdot$ Indiana-Purdue University.
}

stable in polyelectrolyte complexes or coacervates. ${ }^{7-9}$ Thus, investigations of basic aspects of coacervation of proteinpolyelectrolyte complexes provide a foundation not only for the basic understanding of these supramolecular structures but also for their practical applications to protein-related industrial processes.

In the past, several systematic investigations of micro- and macroscopic phase behavior have been carried out in aqueous solutions of bovine serum albumin (BSA) and poly(dimethyldiallylammonium chloride) (PDADMAC). These revealed that BSA-PDADMAC interactions initially lead to soluble "primary complexes". The subsequent coacervation process may be described either as stoichiometric or nonstoichiometric. ${ }^{10,11}$ Two specific $\mathrm{pH}$ values, $\mathrm{pH}_{\text {crit }}$ and $\mathrm{pH}_{\phi}$, were used to parametrize the phenomenological results. Primary complex formation, initiated at $\mathrm{pH}_{\text {crit }}$, was viewed as a microscopic transition on the molecular scale, whereas coacervate droplet formation at $\mathrm{pH}_{\phi}$ was viewed as a global phase transition associated with a characteristic length scale of $10-100 \mathrm{~nm} \cdot{ }^{12,13}$ Factors affecting $\mathrm{pH}_{\text {crit }}$ and $\mathrm{pH}_{\phi}$ values were examined by a variety of experimental methods including static, dynamic, and electrophoretic light scattering measurements. It was found that $\mathrm{pH}_{\phi}$ but not $\mathrm{pH}_{\text {crit }}$ was a function of BSA/PDADMAC ratio. ${ }^{14 a} \mathrm{pH}_{\text {crit }}$ is seen as the point of incipient polycation binding which occurs when some sufficient local negative charge develops on the protein and is related but not equivalent to the isoelectric point of 

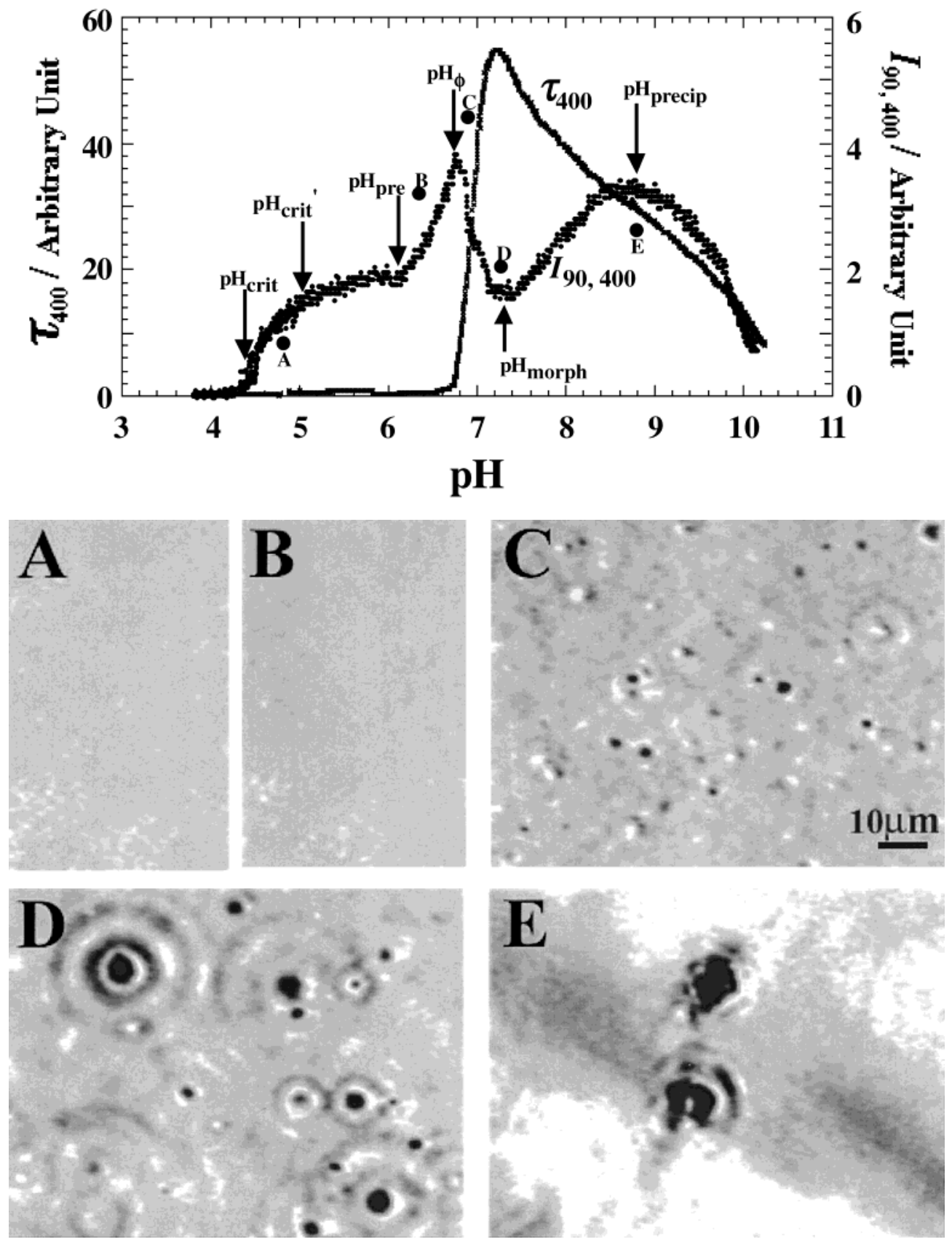

Figure 1. Typical $\mathrm{pH}$ profile of turbidity, $\tau$, and scattering intensity, $1_{90}$, for $r=22.4$ and $\mathrm{NaCl}$ concentration of $100 \mathrm{mM}$ at $25^{\circ} \mathrm{C}$. Arrows indicate specific $\mathrm{pH}$ points, $\mathrm{pH}_{\text {crit }}, \mathrm{pH}_{\text {crit }}, \mathrm{pH}_{\text {pre }}, \mathrm{pH}_{\phi}, \mathrm{pH}_{\text {morph }}$, and $\mathrm{pH}_{\text {precip. }}$ Black dots identified by $\mathrm{A}-\mathrm{E}$ refer to the point where the phase contrast microscope images $\mathrm{A}-\mathrm{E}$ are taken. The scale bar in the microscope image is $10 \mu \mathrm{m}$.

$\mathrm{BSA}, \mathrm{pI}=4.9$ : Since $\mathrm{pH}_{\text {crit }}$ corresponds to some local excess negative charge, it can occur below pI. But, since $\mathrm{pH}_{\phi}$ is thought to involve formation of a charge-neutralized complex, it cannot be observed below pI. ${ }^{10}$ Some of the questions that remain unanswered require that the experimental domain be extended to explain the phase separation processes. This should provide further insight into the nature of the molecular interactions in protein-polyelectrolyte systems.

The aim of the present study is to follow the process of BSA-PDADMAC complexation and subsequent coacervation in the $\mathrm{pH}$ range of $\mathrm{pH}_{\text {crit }}$ to $\mathrm{pH}_{\phi}$, by continuous measurement of turbidity and light scattering intensity with increasing $\mathrm{pH}$. In addition, phase contrast microscopy was used for the direct observation of microcoacervate droplets after the onset of coacervation.

\section{Materials and Methods}

Materials. Poly(dimethyldiallylammonium chloride) (PDADMAC) was a gift from Toa Synthetic Co. Ltd., Japan. The crude sample was purified by fractional precipitation from methanol/acetone mixture. The molecular weight of the purified PDADMAC was estimated as $M_{\mathrm{n}}=1.5 \times 10^{5}$ using a Knauer membrane osmometer equipped with a Knauer Y1244 membrane (5 $\mathrm{nm}$ porosity). Poly(2-methacryloxyethyltrimethylammmonium chloride) (PMETAC) was obtained by thermal polymerization $\left(60^{\circ} \mathrm{C}, 3 \mathrm{~h}\right)$ of methacryloxyethyltrimethylammmonium chloride (Polysciences Inc.) in aqueous phase under $\mathrm{N}_{2}$ atmosphere. The crude sample was purified by fractional precipitation from acetone/water mixture and ultrafiltration, followed by freeze-drying. The 
molecular weight estimated by membrane osmometry was $M_{\mathrm{n}}=1.7 \times 10^{5}$. Bovine serum albumin ( $>96 \%$ purity) was obtained from Sigma Chemical Co. and used without further purification. Doubly distilled water was used to prepare all solutions.

Titrations. Gradual increase in $\mathrm{pH}$ of BSA-PDADMAC solution (referred to elsewhere as "Type I titrations"15) was carried out by addition of metal hydroxide solution to a protein-polyelectrolyte solution with appropriate ionic strength, BSA/PDADMAC ratio, and an initial $\mathrm{pH}$ adjusted with 0.5 $\mathrm{M} \mathrm{HCl}$ to ca. 4. Each $80 \mathrm{~mL}$ sample solution was prepared with a constant concentration of BSA, $0.60 \mathrm{~g} / \mathrm{L}$. The BSA/ PDADMAC weight ratio, $r$, was varied from 1 to 100 . Metal hydroxide titrant solutions containing the same concentrations of metal chlorides as the sample solutions were made up to $\mathrm{pH} 12.5$ and injected into sample solutions using a syringe pump (KD Scientific model 100) with a constant flow rate of $0.95 \mu \mathrm{L} / \mathrm{s}$. The values of $\mathrm{pH}$ characterizing the initiation of primary complex formation and subsequent microcoacervate droplet formation, " $\mathrm{pH}_{\text {crit }}$ " and " $\mathrm{pH}_{\phi}$ ", were not appreciably affected by the titrant injection rate, from 0.12 to $3.8 \mu \mathrm{L} / \mathrm{s}$, and both could be reported with a precision of at least $\pm 0.4 \mathrm{pH}$ units. Titrations were carried out at $25.0 \pm$ $0.1{ }^{\circ} \mathrm{C}$, using a thermostatic water bath, monitoring the $\mathrm{pH}$ $( \pm 0.01 \mathrm{pH}$ units) with a Horiba D-13 pH meter.

Values of the $\mathrm{pH}$ of the sample solution at the end of titration were around $\mathrm{pH} \mathrm{10}$, and dilutions of BSA and PDMDAAC were less than 5\%. Within the $\mathrm{pH}$ ranges studied, 4-10, no irreversible conformational changes of BSA are induced at ambient temperature. ${ }^{16}$ However, at temperatures above $50{ }^{\circ} \mathrm{C}$, where thermal denaturation induces protein unfolding, solid precipitates or flocs were observed. That PDADMAC per se did not induce protein conformation change was borne out by limited circular dichroism measurements which yielded identical circular dichroism spectra in the presence and absence of bound PDADMAC chains.

Spectroscopic Measurements and Microscopic Observations. The progress of the association and aggregation phenomena was monitored via the turbidity at $400 \mathrm{~nm}$, using a Hitachi 200-10 spectrophotometer, and by $90^{\circ}$ light scattering intensity measurements at the same wavelength using a Hitachi 650-10S fluorescence spectrophotometer. A phase contrast microscope (Olympus IMT-2) was used to monitor the later stages of phase separation. Sample solutions under titration were delivered and circulated by a Gilson Minipuls 2 multichannel peristaltic pump into two temperature-regulated photometric cells and simultaneously to a microscopic observation cell on the temperature-regulated stage (Tokai Hit MATS-555RT). All measurements and microscopic observations were carried out at $25.0 \pm 0.1^{\circ} \mathrm{C}$. The time courses of the two kinds of spectrophotometric data and $\mathrm{pH}$ data were recorded on a multiple channel recorder to obtain the $\mathrm{pH}$ dependence of turbidity and scattering intensity.

Phase contrast microscopic images were recorded using CCD video camera equipment (Hamamatsu Photonics C-3077C3754) with an image processor (Hamamatsu Photonics

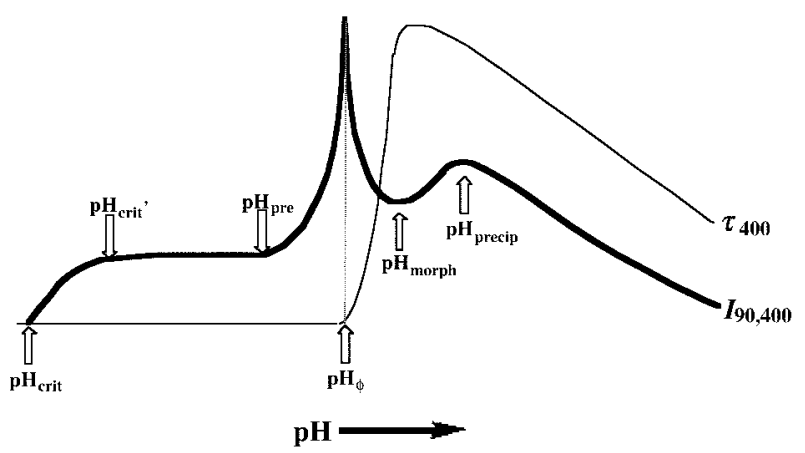

Figure 2. Schematic representation of characteristic $\tau$ and $l_{90}$ profile.
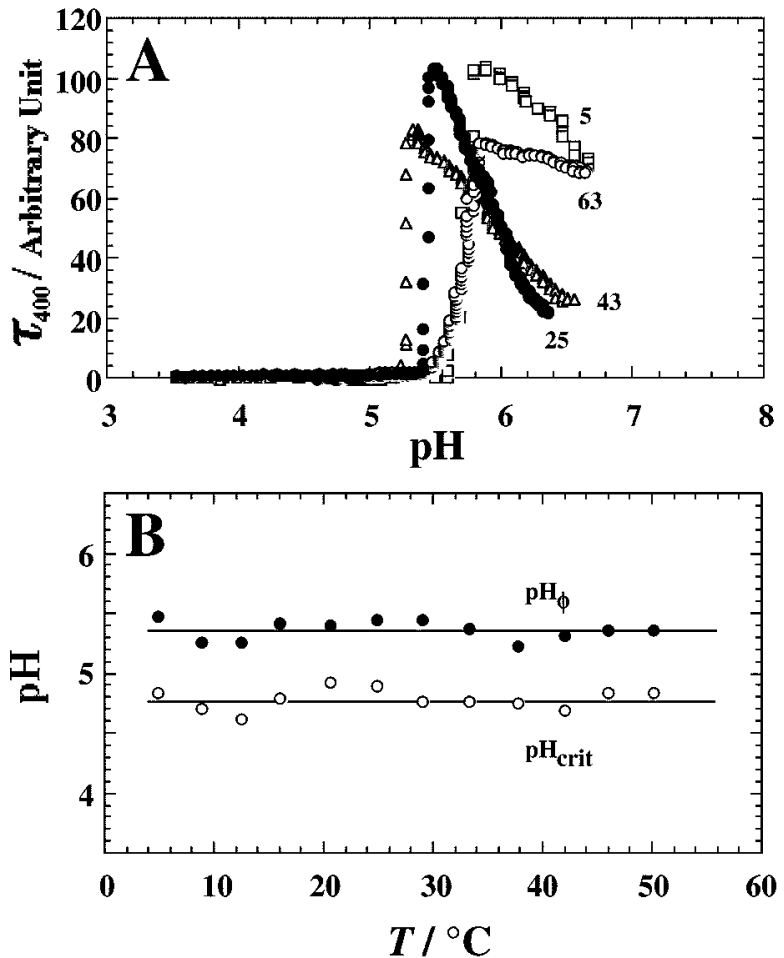

Figure 3. (A) $\mathrm{pH}$ profiles of turbidity, $\tau_{400}$, for $r \cong 24$ and $C_{\mathrm{NaCl}}=10$ $\mathrm{mM}$ at various temperatures: $\square, 5^{\circ} \mathrm{C} ; \bullet, 25^{\circ} \mathrm{C} ; \triangle, 43^{\circ} \mathrm{C} ; \mathrm{O}, 63^{\circ} \mathrm{C}$. (B) Temperature independence of $\mathrm{pH}_{\text {crit }}(\bigcirc)$ and $\mathrm{pH}_{\phi}(\bullet)$

Argus-10) and saved on a video cassette recorder. Microcoacervate droplets were detected as spherical or, occasionally, oval-shaped particles under steady Brownian motion in the equilibrium solution phase. Solid precipitates or flocks observed at higher $\mathrm{pH}$ were easily discriminated from coacervate droplets by phase contrast microscopic observations in the liquid state.

\section{Results and Discussion}

Phenomenology of the pH-Induced Coacervation Process: Identification of $\mathbf{p H}_{\text {crit }}, \mathbf{p H}_{\text {crit }}, \mathrm{pH}_{\text {pre }}, \mathrm{pH}_{\phi}, \mathrm{pH}_{\text {morph }}$, and $\mathbf{p H}$ precip. Figure 1 shows a typical example of the $\mathrm{pH}$ dependence of turbidity $(\tau)$ and $90^{\circ}$ light scattering intensity $\left(I_{90}\right)$ in sample solutions containing $100 \mathrm{mM} \mathrm{NaCl}$ with BSA/ PDADMAC weight ratio, $r=22.4$, at $25.0^{\circ} \mathrm{C}$. Phase contrast microscope images $(\mathrm{A}-\mathrm{E})$ taken at specific stages of phase separation behavior, points $\mathrm{A}-\mathrm{E}$, are correlated with the $\mathrm{pH}$ profiles of spectrophotometric traces in Figure 1. The coacervation process as a function of increasing $\mathrm{pH}$ can be 

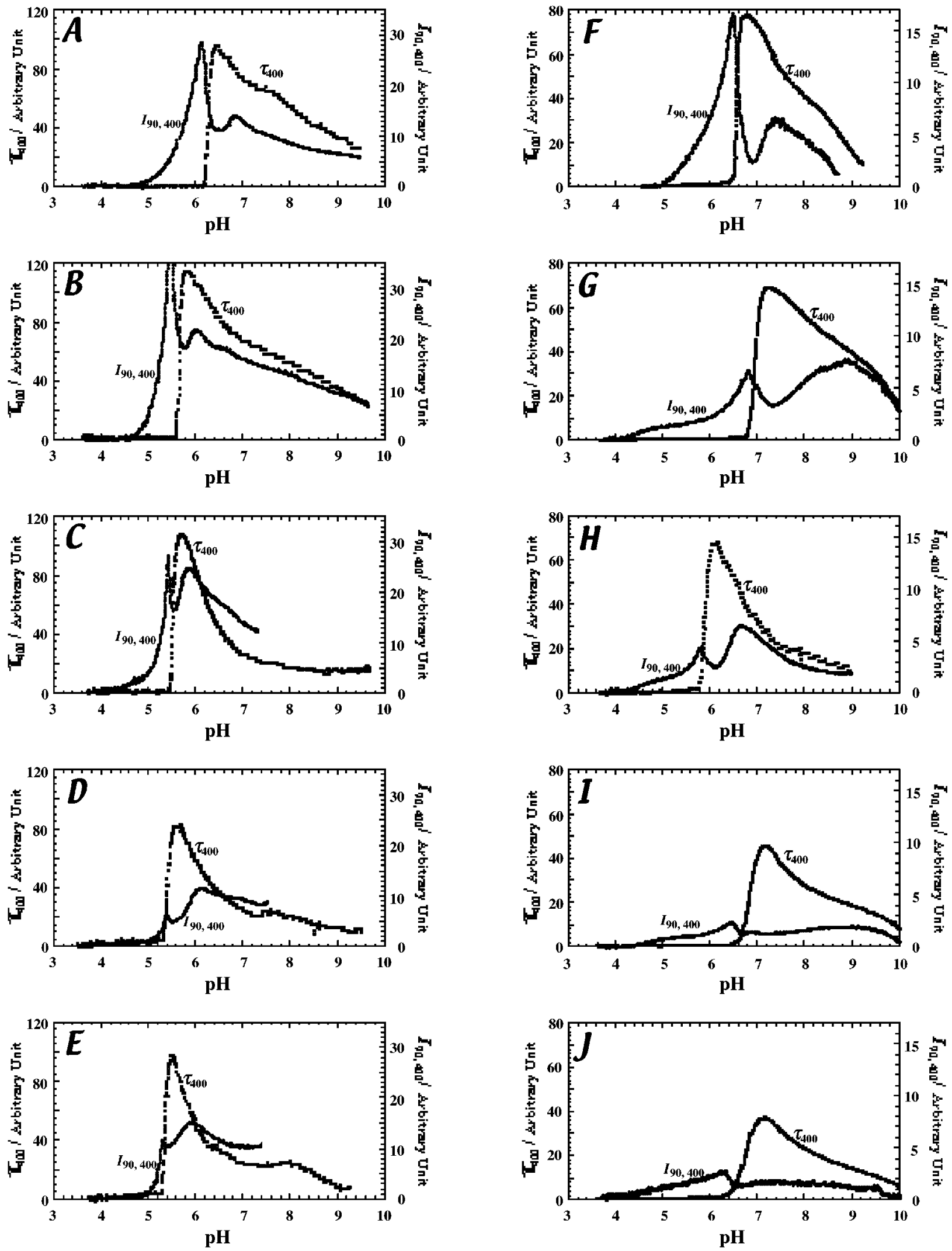

Figure 4. Summary of the $\mathrm{pH}$ profiles of turbidity, $\tau$, and $90^{\circ}$ scattering intensity, l90, at low $\mathrm{NaCl}$ concentration, $10-20 \mathrm{mM}(\mathrm{A}-\mathrm{E})$, and high $\mathrm{NaCl}$ concentration, 50-100 mM (F-J), with varying BSA/PDADMAC ratio, $r\left(C_{\mathrm{NaCl}}(\mathrm{mM}), r\right):(A) 20,5.12 ;(B) 10,9.28$; (C) 10, 19.8; (D) 20, 48.15; (E) 10, 89.00; (F) 50, 4.72; (G) 100, 10.17; (H) 50, 22.17; (I) 100, 48.97; (J) 100, 84.3.

described in terms of a set of specific $\mathrm{pH}$ values corresponding to the limits of different regions of phase behavior. We first note that the scattering intensity, $I_{90}$, departs from a constant value and displays a gradual increase at $\mathrm{pH} 4.3$, below the isoelectric point $\mathrm{pI}=4.9$. After this " $\mathrm{pH}_{\text {crit }}$ ", $I_{90}$ attains a constant level at $\mathrm{pH}$ around 5 (" $\mathrm{pH}_{\text {crit }}$ "). Following the plateau, a second increase is initiated at $\mathrm{pH} 6.2$ (" $\mathrm{pH}_{\text {pre") }}$ ). Particles were not observed in phase contrast microscopic 
images taken at either $\mathrm{pH} 4.8$ (A) or $\mathrm{pH} 6.4$ (B). The maximum scattering intensity was observed at $\mathrm{pH}$ 6.8; at this same point (" $\mathrm{pH}_{\phi}$ "), $\tau$ started to increase. The turbidity attained a maximum at $\mathrm{pH}=7.2$ and then gradually decreased. The maximum in tubidity was accompanied by a minimum in $I_{90}$. As the $\mathrm{pH}$ exceeded $8, I_{90}$ displayed a second maximum at $\mathrm{pH}$ 8.8. Phase contrast microscopic observations detected the first appearance of microcoacervate droplets under steady Brownian motion at $\mathrm{pH} 6.8$ (point "C"), with subsequent increase in size and decrease in number of droplets at $\mathrm{pH} 7.2$ ( $\mathrm{pH}_{\text {morph }}$ ) (point "D"). At a final stage of the phase separation behavior, morphological changes of coacervate droplets in liquid state to solid precipitates or flocks were observed at $\mathrm{pH} 8.8$ ( $\mathrm{pH}_{\text {precip }}$ ) (point “E”).

The titration profiles in Figure 1, schematically represented for greater clarity in Figure 2, suggest the following interpretations. The possibility that such drastic scattering effects could arise from protein-protein interactions can be excluded based on observations of constant diffusion coefficient and low apparent polydispersity from dynamic light scattering studies in the range $4<\mathrm{pH}<10 .{ }^{14 \mathrm{~b}}$ Soluble "primary" complexes form at $\mathrm{pH}_{\text {crit }}$ near the isoelectric $\mathrm{pH}$ of BSA. Since binding of polymer to protein involves a local, not global, negative domain, this may occur at $\mathrm{pH}<\mathrm{pI}^{14,22}$ Soluble complex formation is completed at $\mathrm{pH}_{\text {crit. }}$ As the titration progresses there is a concomitant increase in protein negative charge. However, scattering from primary complexes remains constant until $\mathrm{pH}=\mathrm{pH}_{\mathrm{pre}}$ at which point aggregation of primary complex is initiated. Separation of microcoacervate droplets is induced at $\mathrm{pH}=\mathrm{pH}_{\phi}$. In the turbid solution above $\mathrm{pH}_{\phi}, \tau$ and $I_{90}$ values fluctuate vigorously due to the rapid droplet number density and shape fluctuations. This accompanies precipitation of solid or flocculant substances. Microscopic observations suggest the existence of $\mathrm{pH}_{\text {morph }}$ and $\mathrm{pH}_{\text {precip }}$ in the later stage of phase separation. We examined these specific $\mathrm{pH}$ values as a function of $r$, ionic strength, and temperature, focusing in particular on the exact identification of $\mathrm{pH}_{\text {crit }}$ and $\mathrm{pH}_{\phi}$.

Effect of Temperature. The microscopic and macroscopic states of this system are highly sensitive to $\mathrm{pH}$. Rapid turbidity increases corresponding to phase separation take place within less than $0.2 \mathrm{pH}$ units as shown in Figure 1 . Since the sole effect of $\mathrm{pH}$ is on the charge state of BSA, these results suggest that electrostatic interaction is the dominant factor in BSA-PDMDAAC coacervation. If hydrophobic interactions contribute, it should be possible to observe temperature dependence of phase behavior, since hydrophobic interactions are known to exhibit strong temperature dependence. ${ }^{17}$ As shown in Figure $3 \mathrm{~B}, \mathrm{pH}_{\text {crit }}$ and $\mathrm{pH}_{\phi}$ values are almost independent of temperature up to 50 ${ }^{\circ} \mathrm{C}$ in sample solutions with $r=24$ and ionic strength of 10 $\mathrm{mM} \mathrm{NaCl}$. Even above $50{ }^{\circ} \mathrm{C}$, where thermal unfolding of $\alpha$-helical structure of BSA may occur, ${ }^{18} \mathrm{pH}_{\phi}$ still remained constant, although the separated phase components were solid precipitates or flocs, not microcoacervate droplets. The distinction is indicated by the turbidity $\mathrm{pH}$ profiles shown in Figure 3A. Note the turbidity scale is chosen to display the entire curve and lacks the resolution actually used to identify $\mathrm{pH}_{\text {crit. }}$ This temperature independence of $\mathrm{pH}$-induced
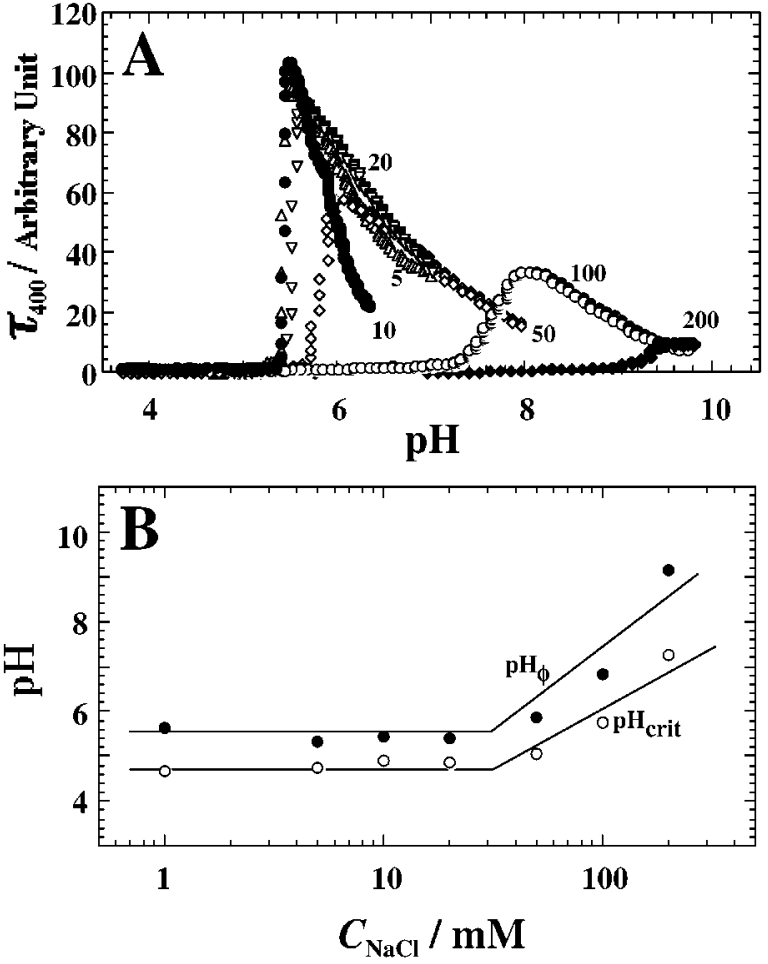

Figure 5. (A) Effects of $\mathrm{NaCl}$ concentration on the $\mathrm{pH}$ profiles of turbidity, $\tau_{400}$, at $25^{\circ} \mathrm{C}$ and $r \cong 24:(\triangle) 5 \mathrm{mM} ;(\bullet) 10 \mathrm{mM} ;(\nabla) 20$ $\mathrm{mM}$; $(\diamond) 50 \mathrm{mM}$; (О) $100 \mathrm{mM}$; $\diamond) 200 \mathrm{mM}$. (B) Dependences of $\mathrm{pH}_{\text {crit }}$ $(\bigcirc)$ and $\mathrm{pH}_{\phi}(\bullet)$ on $\mathrm{C}_{\mathrm{NaCl}}$.

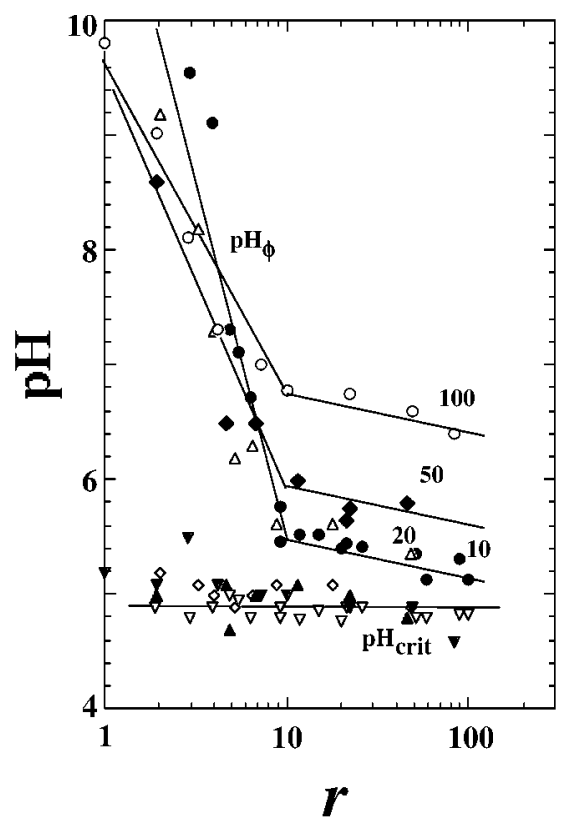

Figure 6. Dependence of $\mathrm{pH}_{\text {crit }}$ and $\mathrm{pH}_{\phi}$ on $r$ at various $\mathrm{NaCl}$ concentrations. The $\mathrm{pH}_{\text {crit }}$ and $\mathrm{pH}_{\phi}$ at respective $\mathrm{NaCl}$ concentrations are: $\nabla, \bullet(10 \mathrm{mM}) ; \diamond, \Delta(20 \mathrm{mM}) ; \Delta, \diamond(50 \mathrm{mM}) ;$ and $\boldsymbol{\nabla}, \bigcirc(100$ $\mathrm{mM})$.

coacervation of BSA-PDADMAC implies that the contribution of hydrophobic interactions to phase behavior is negligible. These results are in contrast to those for systems in which coacervation may comprise hydrophobic contributions or other entropy-dominated effects. For example, complex formation between PDADMAC and anionic micelles displays temperature-induced phase separation..$^{19}$ Aqueous solutions of polypeptides related to the elastomeric 

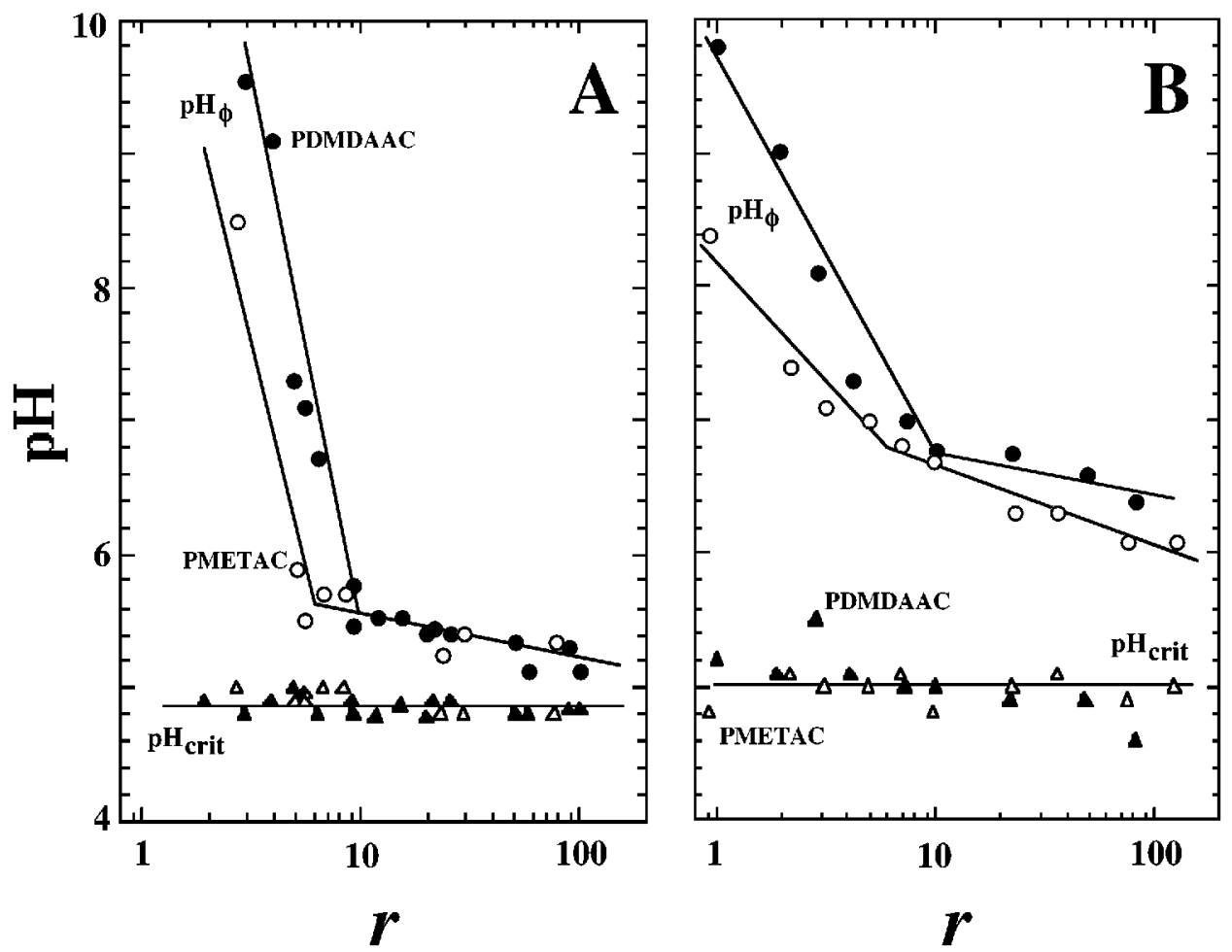

Figure 7. Dependence of $\mathrm{pH}_{\text {crit }}$ and $\mathrm{pH}_{\phi}$ on $r$ for PDADMAC

and $\mathbf{\Delta})$ and PMETAC ( $\bigcirc$ and $\square)$ systems:

(A) $10 \mathrm{mM} \mathrm{NaCl}$; (B) $100 \mathrm{mM} \mathrm{NaCl}$.

protein, elastin, are known to coacervate upon heating to body temperature. The temperature-dependent coacervation of elastin-related polypeptides can in fact be mimicked by an uncharged synthetic model peptide system, where molecular interactions are essentially hydrophobic. ${ }^{20,21}$

Effects of Ionic Strength and $\boldsymbol{r}$. Figure 4 shows $\mathrm{pH}$ profiles of $\tau$ and $I_{90}$ collected from the time tracings of spectrophotometric data and $\mathrm{pH}$ changes, at different BSA/ PDADMAC weight ratios, $r=1-100$, and $\mathrm{NaCl}$ concentrations, $C_{\mathrm{NaCl}}=10-100 \mathrm{mM}$. The essential features of $\mathrm{pH}-$ dependent changes in $\tau$ and $I_{90}$ values are similar to those mentioned in the discussion of Figure 1 and depicted in Figure 2. The identification of $\mathrm{pH}_{\text {crit }}$ and $\mathrm{pH}_{\text {pre }}$ is less evident in Figure 4 than in Figure 1 due in part to the scale of the figure but also to the shape of the curves. However, $\mathrm{pH}_{\text {crit }}$ and $\mathrm{pH}_{\phi}$ could be readily determined to $\pm 0.4 \mathrm{pH}$ units or better. Figure 5A shows the effects of $C_{\mathrm{NaCl}}$ on turbidimetric plots near $\mathrm{pH}_{\phi}$ at $25^{\circ} \mathrm{C}$ and $r=24$, and the corresponding $\mathrm{pH}_{\phi}$ vs $C_{\mathrm{NaCl}}$ relationship is shown in Figure 5B. At $C_{\mathrm{NaCl}}$ below $30 \mathrm{mM}, \mathrm{pH}_{\phi}$ is nearly independent of $C_{\mathrm{NaCl}}$, while above this concentration, both $\mathrm{pH}_{\text {crit }}$ and $\mathrm{pH}_{\phi}$ values tend to increase, with $\mathrm{pH}_{\phi}$ attaining values up to $9-10$ at $C_{\mathrm{NaCl}}$ of $200 \mathrm{mM}$.

Effects of $r$ and $C_{\mathrm{NaCl}}$ on $\mathrm{pH}_{\text {crit }}$ and $\mathrm{pH}_{\phi}$ are summarized in Figure 6. The lines are intended to guide the eye and to indicate a qualitative change in $r$ dependence in the vicinity of $r=10$ and are not particularly fitted to data at small $r$. At low $r$ values, e.g., $1-3$, initiation of the coacervation process required high $\mathrm{pH}$ values around 9-10. $\mathrm{pH}_{\phi}$ values decreased rapidly with increasing $r$ up to $r=10$. Beyond $r$ $=10$, the variation of $\mathrm{pH}_{\phi}$ with $r$ was significantly suppressed to ca. $0.2 \mathrm{pH}$ units for $10<r<100$. With regard to the effect of salt, for $r>10, \mathrm{pH}_{\phi}$ increased with increasing $C_{\mathrm{NaCl}}$, corresponding to a higher charge on BSA in the primary complex at the point of coacervate droplet formation. On the other hand, for $r<10$, systematic effects of $C_{\mathrm{NaCl}}$ on $\mathrm{pH}_{\phi}$ were difficult to observe. This "threshold" value of $r=$ 10 was independent of $\mathrm{NaCl}$ concentration. To explain the significance of this discontinuity, we suggest that PDADMAC is saturated with BSA at $r=10$, corresponding to ca. 20 BSA molecules bound per PDADMAC chain, corresponding to, i.e., ca. 40 charged sites of PDADMAC per bound BSA molecule. This number of BSA molecules per PDADMAC chain agrees with results obtained under comparable conditions by spectroscopic estimation of BSA concentrations in the centrifuged upper layer separated from the coacervate phase. ${ }^{22} \mathrm{In}$ the $\mathrm{pH}$ range $6-10$, the charge on BSA, $Z$, is given empirically as $Z=26.4-6.0 \mathrm{pH} .^{10,23}$ In the case of $r=10$ and $100 \mathrm{mM} \mathrm{NaCl}$, it can be estimated from $\mathrm{pH}_{\phi}=6.8$ that $Z=-14$. Strictly speaking, this relation applies to free BSA and not to bound proteins for which $\mathrm{p} K_{\mathrm{a}}$ values may be somewhat shifted. ${ }^{24 a}$ The shift is significant only at $\mathrm{pH}>6$ and $I<50 \mathrm{mM}$ and could result in values of $Z$ more negative by as much as $30 \%$. Regardless of this we can conclude that the number of protein negative charges is substantially less than the number of polymer (positive) charges, so coacervation neutralization requires a very significant amount of small negative ions.

Under the conditions of $r \ll 10$, it is reasonable to assume that the PDADMAC chains are not saturated with BSA molecules, and excess free polymers may exist in solution phase. Accordingly, further addition of $\mathrm{OH}^{-}$ions and increased negative protein charge is required to achieve the charge neutralization of BSA-PDADMAC complexes that leads to protocoacervate formation. For $r \gg 10$, PDMDAAC chains are saturated with BSA molecules coexisting with free BSA. Since complexes are saturated, microstoichiometry is not affected by macrostoichiometry and the affect of $r$ on 


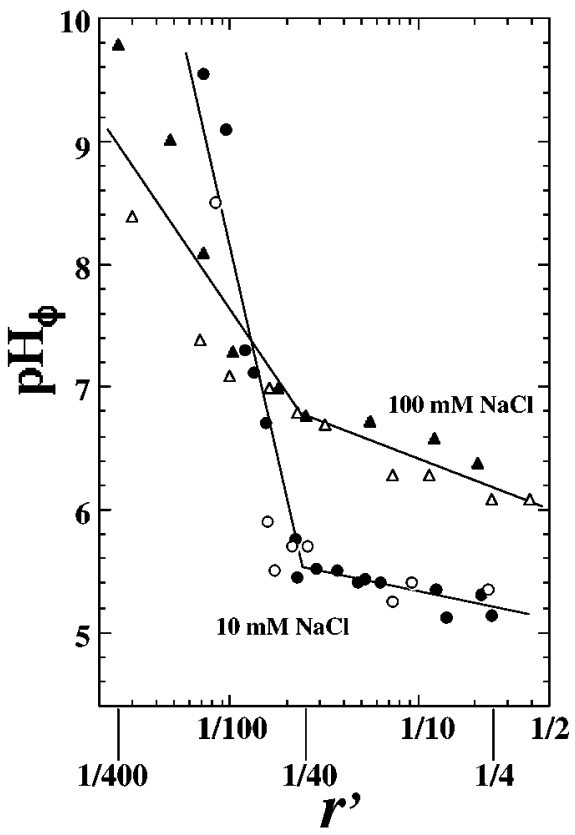

Figure 8. Relationships between $\mathrm{pH}_{\phi}$ values and reduced $r$ for PDMDAAC ( $\bullet$ and $\mathbf{\Delta})$ and PMETAC $(O$ and $\triangle)$ systems. $\mathrm{NaCl}$ concentration: $(\bullet, \bigcirc) 10 \mathrm{mM} ;(\boldsymbol{\Lambda}$ and $\Delta) 100 \mathrm{mM}$. The reduced $r^{\prime}=$ $r \times(\mathrm{MW}$ of polyelectrolyte monomer unit/MW of BSA) refers to the reciprocal number of charged sites of polyelectrolyte per BSA molecule.

$\mathrm{pH}_{\phi}$ is less than $0.2 \mathrm{pH}$ units as $r$ increases from 10 to 100 . In these situations, polymer-free BSA molecules were indeed detected directly by the light-scattering experiments. ${ }^{24 \mathrm{~b}}$

Effects of Polyelectrolyte Charge Density. PDADMAC was replaced by poly(2-methacryloxyethyltrimethylammonium chloride) (PMETAC, $M_{\mathrm{n}} 1.7 \times 10^{5}$ ) with essentially twice the linear charge density. The "threshold" $r$ values for the PMETAC system (around 6-7) were somewhat lower than those for PDMDAAC; however, both systems revealed almost identical $\mathrm{pH}_{\phi}$ values at the $\mathrm{NaCl}$ concentrations shown in Figure 7. If we introduce the reduced BSA/polyelectrolyte weight ratio $r^{\prime}$, defined as $(r) \times$ (polyelectrolyte monomer unit mass/BSA molecular weight), $r^{\prime}$ can be related to the reciprocal number of charged sites of polyelectrolyte per

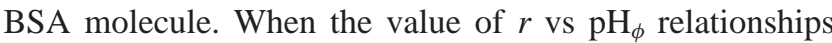
was transferred to the reduced $r^{\prime}$ axis as shown in Figure 8, both PDADMAC and PMETAC systems exhibit nearly equivalent plots of $\mathrm{pH}_{\phi}$ vs $\mathrm{BSA} / \mathrm{monomer}$ residue molar concentration ratio. This result suggests that the number of polymeric charged sites per BSA molecule controls the coacervation processes and is consistent with electrostatic interactions between BSA and PDADMAC or PMETAC. Density and structural differences of charged site among polymeric chains had little effect on the coacervation process.

Microscopic Observation of Phase-Separated Droplets: Late Stages of pH-Induced Coacervation. Static and dynamic light scattering methods, useful for investigation of the early stages of coacervation, are inapplicable when turbidity increases from microcoacervate droplet formation. Direct observation of the droplets by phase contrast microscopy may then be used to trace the phase behavior in late stages, as shown in Figure 1. Soluble BSA/PDADMAC complexes, presumably formed at $\mathrm{pH}_{\text {crit }}$, could not be detected by phase contrast microscopy, but upon increase
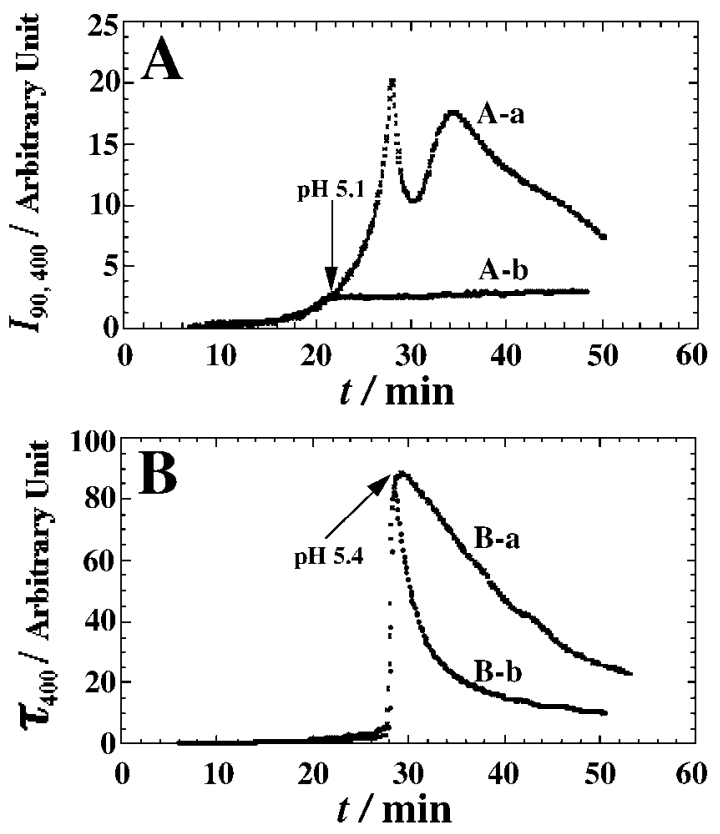

Figure 9. (A) Time courses of 190 with continuous titration $(A-a)$ and with titration interrupted at $\mathrm{pH} 5.1(\mathrm{~A}-\mathrm{b})$. (B) time courses of $\tau_{400}$ with continuous titration (B-a) and with titration interrupted at $\mathrm{pH} 5.4$ (Bb). $\mathrm{NaOH}$ titrant solution ( $\mathrm{pH} 12.5$ ) was injected at $0.95 \mu \mathrm{L} / \mathrm{s}, r=24$, and $C_{\mathrm{NaCl}}=10 \mathrm{mM}$.

of $\mathrm{pH}$ close to $\mathrm{pH}_{\phi}$, microcoacervate droplets exhibiting Brownian motion were observed. The sizes of the droplets observed just after the initiation of phase separation, around $1 \mu \mathrm{m}$ in diameter, were not appreciably affected by $r$ or $C_{\mathrm{NaCl}}$, but the number of droplets decreased with increasing ionic strength. Further increase in $\mathrm{pH}$ above $\mathrm{pH}_{\phi}$ induced an increase in droplet size, up to $10 \mu \mathrm{m}$, and a decrease in the number of droplets in many cases at around " $\mathrm{pH}_{\text {morph" }}$. These enlarged droplets displayed further morphological changes; finally, solid precipitates or flocs were commonly observed at $\mathrm{pH}$ around $\mathrm{pH}_{\text {precip. }}$. These microscopic observations on size, number, and shape of the phase-separated droplets were well correlated with the results of turbidity formation and scattering intensity measurements.

Possible BSA-PDADMAC Interactions and Phase Behavior: Concluding Remarks. The following scenario describes the molecular process by which electrostatic interactions of BSA with PDADMAC eventually result in the separation of a coacervate phase containing concentrated BSA. The $\mathrm{pH}$ profiles of scattering intensity, $I_{90}$, indicate that binding of BSA to the PDADMAC chain is completed within the $\mathrm{pH}$ range from " $\mathrm{pH}_{\text {crit }}$ " to " $\mathrm{pH}_{\phi}$ ". Despite an increase in protein negative charge, the concentration and the state of the complex remain constant up to " $\mathrm{pH}_{\text {pre }}$ ". When the titration with $\mathrm{NaOH}$ solution is interrupted in these $\mathrm{pH}$ regions, spectrophotometric data and $\mathrm{pH}$ values remain constant, the former as shown in Figure 9A-b. The region $\mathrm{pH}_{\text {crit }}<\mathrm{pH}<\mathrm{pH}_{\text {pre }}$ may thus be identified as the region of stable intrapolymer complexes. Upon progress of titration, associated with increase in the negative charge on BSA, i.e., with approach to electroneutrality, the onset of a second increase in $I_{90}$ at " $\mathrm{pH}_{\mathrm{pre}}$ " is an indication of the aggregation of primary complexes. The aggregation of primary complexes, a preliminary step to coacervation, progresses up to the point of maximal scattering intensity, at which point the 
turbidity increases abruptly at " $\mathrm{pH}_{\phi}$ ". Below $\mathrm{pH}_{\phi}$, no visible particles were observed under a phase contrast microscope although slight increases in $\tau$ values at $\mathrm{pH}_{\text {crit }}$ are noticed in some systems. Even at $\mathrm{pH}$ close to $\mathrm{pH}_{\phi}$, only a few particles were occasionally detected by phase contrast microscopy.

In all the systems studied, the scattering intensity maximum and the onset of abrupt turbidity increase were found to be in close proximity at $\mathrm{pH}_{\phi}$. In these situations, if the titration with $\mathrm{NaOH}$ solution was interrupted, stable $\mathrm{pH}$ conditions were hard to maintain and phase separation continued to occur (see Figure 9B-b). Beyond $\mathrm{pH}_{\phi}, \tau$ and $I_{90}$ both showed unstable $\mathrm{pH}$-dependent changes in turbid solution. Regardless, the turbidity maximum was usually observed close to the scattering intensity minimum at around " $\mathrm{pH}_{\text {morph". Slightly above }} \mathrm{pH}_{\phi}$, spherical microcoacervate droplets with relatively uniform diameter of around $1 \mu \mathrm{m}$ under steady Brownian motion were observed; however, a further increase in $\mathrm{pH}$ readily caused an increase in the size and a decrease in the number of these coacervate droplets, which in some cases transformed from spherical to elliptic shape. Phase contrast microscopic observations detected changes in droplet characteristics at around " $\mathrm{pH}_{\text {morph" }}$ " and formation of solid precipitate or flocculant substance at around " $\mathrm{pH}_{\text {precip }}$ ".

Inspection of turbidimetric and scattering profiles of the PDMDAAC-BSA system leads to the identification of several features which appear to correspond to various transitions at different length scales. These phenomenological transitions are identified as $\mathrm{pH}_{\text {crit }}, \mathrm{pH}_{\text {crit }}^{\prime}, \mathrm{pH}_{\text {pre }}, \mathrm{pH}_{\phi}, \mathrm{pH}_{\text {morph }}$, and $\mathrm{pH}_{\text {precip }}$, and they show different dependence on two key variables, the protein/polymer weight ratio, $r$, and the concentration of simple salt. The most clearly defined transition points, $\mathrm{pH}_{\text {crit }}$ and $\mathrm{pH}_{\phi}$ correspond to $\mathrm{pH}$-induced soluble complex formation and $\mathrm{pH}$-induced coacervation. In general, the former depends on salt concentration but not on $r$; the latter may depend on both. Howrever, as may be seen from Figures 5 and $6, \mathrm{pH}_{\phi}$ becomes constant at $\mathrm{pH}=$ 5.4 under conditions of low salt and large $r$, namely, $C_{\mathrm{NaCl}}$ $<30 \mathrm{mM}$ and $r>10 . \mathrm{pH}_{\phi}$ increases with ionic strength for $C_{\mathrm{NaCl}}=50 \mathrm{mM}$ and higher, notably for $r>10$. Figures 6 and 7 reveal that, regardless of ionic strength, $\mathrm{pH}_{\phi}$ depends only on $r$ when $r<10$. Last, and rather remarkably, $\mathrm{pH}_{\phi}$ exhibited no temperature dependence. This final result seems to support the assumption that complexation does not include a strong contribution from hydrophobic interactions.

The current, essentially phenomenological, work explores a wide range of system variables and thus provides a foundation for future studies in several directions. Numerous scattering, hydrodynamic, and electrophoretic techniques can elucidate the evolution of complex structure with changes in solution conditions. With regard to theoretical interpretation, we note that some of the above-mentioned features have been described by physical models of polyelectrolytes and charged spheres. ${ }^{7,12,24-29} \mathrm{Netz}^{25}$ et al. have used three characteristic Debye-Huckel screening lengths in their model to demarcate various interaction zones. The touching or wrapping transition was shown to occur when the charge on the sphere, $Z$, exceeded a threshold value $Z_{\mathrm{t}}$. The parameter $Z_{\mathrm{t}}$ in turn was found to be a function of the diameter of the sphere, the polymer persistence length (intrinsic), the linear charge density of the polymer, and the electrostatic screening length. They ${ }^{25}$ applied this model to discuss the wrapping of DNA to free histone particles. However, most of these models assume a spherical protein molecule of uniform charge interacting with an oppositely charged polymer and, thus, do not take into account the asymmetry of shape and charge intrinsic to the proteins.

Acknowledgment. K. Kaibara acknowledges a Grantin-Aid from the Ministry of Education, Science and Culture of Japan and from the Salt Science Research Foundation (Tokyo, Japan). P. L. Dubin acknowledges support from the National Science Foundation under Grant DMR-9619772 .

\section{References and Notes}

(1) Bungenberg de Jong In Colloid Science; Kruyt, H. R. Ed.; Elsevier: Amsterdam, 1949; Vol. II, Chapter X.

(2) Wang, Y.; Gao, J. Y.; Dubin, P. L. Biotechnol. Prog. 1996, 12, 356.

(3) Nes, W. D. J. Am. Chem. Soc., 1999, 121, 1625.

(4) Menger, F. M.; Sykes, B. M. Langmuir 1998, 14, 4131.

(5) Ichwan, A. M.; Karimi, M.; Dash, A. K. J. Pharm. Sci. 1999, 88, 763.

(6) Strege, M. A.; Dubin, P. L.; West, J. S.; Flinta, C. D. In Protein Purification: from Molecular Mechanisms to Large-Scale Processes; Ladisch, M., Wilson, R. C., Painton, C. C., Builder, S. E., Eds. American Chemical Society: Washington, DC, 1990; Chapter 5.

(7) Thomasin, C.; Nam-Tran, H.; Merkle., H. P.; Gander, B. J. Pharm. Sci. 1998, 87, 259

(8) Thomasin, C.; Merkle, H. P.; Gander, B. J. Pharm. Sci. 1998, 87, 269.

(9) Tsung, M.; Burgess, D. J. J. Pharm. Sci. 1997, 86, 603.

(10) Xia, J.; Dubin, P. L.; Ahmed, L. S.; Kokufuta, E. In Macro-Ion Characterization from Dilute Solution to Complex Fluids; Schmidt, K. S., Ed.; American Chemical Society: Washington, DC, 1994; Chapter 17.

(11) Xia, J.; Dubin, P. L.; Muhoberac, B. B.; Kim, Y. S.; Klimkowski, V. J. J. Phys. Chem., B 1993, 97, 4528.

(12) Zhang, H.; Dubin, P. L.; Ray, J.; Manning, G. S.; Moorefield, C. N.; Newkome, G. R. J. Phys. Chem. 1999, 103, 2347.

(13) Li, Y.; Dubin, P. L.; Spindler, R.; Tomalia, D. A. Macromolecules $1995,28,8426$.

(14) (a) Mattison, K. W.; Dubin, P. L.; Brittain, I. J. Phys. Chem. B 1998, 102, 3830. (b) Park, J. M.S. Thesis, Purdue University, 1991.

(15) Ahmed, L. S.; Xia, J.; Dubin, P. L.; Kokufuta, E. J. Macromol. Sci., Pure Appl. Chem. 1994, A31, 17.

(16) Tanford, C.; Buzzell, J. G.; Rands, D. G.; Swanson, S. A. J. Am. Chem. Soc. 1955, 72, 6421.

(17) Tanford, C. The Hydrophobic Effect: Formation of Micelles and Biomembranes; Wiley: New York, 1980.

(18) Lin, V. J. C.; Koenig, J. L. Biopolymers 1976, 15, 203.

(19) Dubin, P. L.; Vea, Y. E. M.; Fallon, M. A.; The, S. S.; Rigsbee, D. R.; Gan, L. M. Langmuir 1990, 6, 1422.

(20) Luan, C. H.; Harris, R. D.; Prasad, K. U.; Urry, D. W. Biopolymers 1990, 29, 1699.

(21) Kaibara, K.; Okamoto, K.; Miyakawa, K. In New Functionality Materials, Volume B: Synthesis and Function of Biofunctionality Materials; Tsuruta, T., Doyama, M., Seno, M., Imanishi, Y., Eds.; Elsevier Science Publishers BV: Amsterdam, 1993; pp 281-286

(22) Wang, Y.; Gao, Y.; Dubin, P. L. Biotechnol. Prog. 1996, 12, 356.

(23) Tanford, C. J. Am. Chem. Soc. 1950, 72, 441.

(24) (a) Wen, Y.; Dubin, P. L. Macromolecules 1997, 30, 7856. (b) Li, Y.; Mattison, K. W.; Dubin, P. L.; Havel, H. A.; Edwards, S. L. Biopolymers 1996, 38, 527.

(25) Netz, R. R.; Orland, H. Euro. Phys. Lett. 1999, 45, 726. Netz, R. R.; Orland, H. Euro. Phys. J. 1999, B8, 81. Netz, R. R.; Joanny, J. F. Macromolecules 1998, 31, 5123. Netz, R. R.; Schick, M. Macromolecules 1998, 31, 5105. Netz, R. R. Euro. Phys. Lett. 1999, 47, 391. Netz, R. R.; Joanny, J. F. Macromolecules 1999, 32, 9013 and 9026.

(26) Kong, C. Y.; Muthukumar, M. J. Chem. Phys. 1998, 109, 1522.

(27) Burgess, D. J. J. Colloid Interface Sci. 1990, 140, 223.

(28) Von Goeler, F.; Muthukumar, M. J. Chem. Phys. 1994, 100, 7796.

(29) Tricot, M. Macromolecules 1984, 17, 1698.

BM990006K 